\title{
Interleukin-1B-31T/C promoter polymorphism and chronic obstructive pulmonary disease risk: a meta-analysis
}

\author{
Min Xiao ${ }^{1,2}$, Lingli Guo ${ }^{1,2}$, Tao Wang ${ }^{1,2}$, Tao Zhu ${ }^{1,2}$, Liuqun Jia ${ }^{1,2}$, Lei Chen ${ }^{1,2}$, Fuqiang Wen ${ }^{1,2}$
}

\begin{abstract}
'Division of Pulmonary Diseases, State Key Laboratory of Biotherapy of China, West China Hospital, West China School of Medicine, Sichuan University, Chengdu, China 2Department of Respiratory Medicine, West China Hospital, West China School of Medicine, Sichuan University, Chengdu, China
\end{abstract}

Submitted: 6 September 2013

Accepted: 2 November 2013

Arch Med Sci 2014; 10, 3: 434-438

DOI: $10.5114 /$ aoms.2014.43737

Copyright $\odot 2014$ Termedia \& Banach

\section{Abstract}

Introduction: The role of interleukin (IL)- $1 \beta-31 \mathrm{~T} / \mathrm{C}$ promoter polymorphism in the pathogenesis of chronic obstructive pulmonary disease (COPD) has been studied with inconsistent results. This meta-analysis was performed to assess the association of IL-1 $\beta-31 \mathrm{~T} / \mathrm{C}$ promoter polymorphism with COPD susceptibility.

Material and methods: Published case-control studies from PubMed and China National Knowledge Infrastructure (CNKI) databases were retrieved. Data were extracted and pooled odds ratios (OR) with $95 \%$ confidence intervals $(\mathrm{Cl})$ were calculated.

Results: Six case-control studies were included in this meta-analysis. The pooled effect size showed that IL-1 $\beta-31$ T/C was significantly associated with COPD susceptibility in an overdominant genetic model (CC+TT vs. TC, OR: 0.77, $95 \% \mathrm{Cl}: 0.63-0.94$ ), indicating that homozygotes (CC and TT) had a decreased risk for COPD compared with heterozygotes (TC). In the subgroup analysis by ethnicity, the results indicated that IL-1 $\beta-31 \mathrm{~T} / \mathrm{C}$ was significantly correlated with COPD susceptibility in Asians (overdominant model, OR: $0.75,95 \% \mathrm{CI}: 0.61-0.93)$, further suggesting a protective role of IL-1 $\beta$ $-31 \mathrm{~T} / \mathrm{C}$ in COPD pathogenesis in Asians. Moreover, after excluding the study without Hardy-Weinberg equilibrium, the pooled results were robust and no publication bias was found in this study.

Conclusions: This meta-analysis suggests that IL-1 $\beta-31 \mathrm{~T} / \mathrm{C}$ promoter polymorphism confers protection against COPD in Asians.

Key words: chronic obstructive pulmonary disease, interleukin-1 $\beta$, polymorphism.

\section{Introduction}

Chronic obstructive pulmonary disease (COPD) is a worldwide disease, characterized by persistent airflow limitation that is progressive and associated with an enhanced inflammatory response in airways and lungs [1]. To date, although the underlying mechanisms of COPD remain not fully elucidated, a genetic predisposition of COPD has been strongly evidenced [2-4].

Interleukin (IL)-1 $\beta$, a proinflammatory cytokine, is encoded by the IL1B gene on chromosome $2 q 14$, which is identified as a candidate gene

\author{
Corresponding author: \\ Fuqiang Wen MD, PhD \\ Department \\ of Respiratory Medicine \\ West China Hospital \\ Sichuan University \\ Sichuan 610041, P.R. China \\ Phone: 862885422380 \\ Fax: 862885422380 \\ E-mail: wenfuqiang_scu@ \\ 163.com
}


of COPD [5]. In the past decade, the relationship of polymorphisms in the IL1B gene with COPD risk has been well studied, including the $-31 T / C$ promoter polymorphism in the IL1B gene with the potential to alter the transcriptional activity [6]. However, inconsistent results were reported [7-11], which may be owing to differences in ethnicity and sample size in individual studies, resulting in lower statistical power. It is suggested that meta-analysis could be a useful means to pool the independent statistical powers and thus achieve a quantitative understanding of the associations. Accordingly, in the present study, a meta-analysis was performed to determine IL- $1 \beta-31 \mathrm{~T} / \mathrm{C}$ promoter polymorphism and the risk of COPD.

\section{Material and methods}

\section{Search strategy}

The literature search was conducted using PubMed and China National Knowledge Infrastructure (CNKI) (http://www.cnki.net/) databases. CNKI database was founded by Tsinghua University of China in 1996 and includes over 8000 Chinese journals covering natural and social sciences. The languages were limited to English and Chinese. The following search terms were utilized: interleukin 1 beta or interleukin $1 \mathrm{~b}$ or IL1beta or IL1b, and polymorphism or variant or SNP or genotype, and chronic obstructive pulmonary disease or COPD.

\section{Data extraction}

Two independent reviewers collected the data according to the inclusion and exclusion criteria. For inclusion in the meta-analysis, retrieved articles had to inform about the number of cases and controls, and the number of individual genotypes in cases and controls. Exclusion criteria in the meta-analysis were 1) not case-control genetic study, 2) duplicated report, 3) no useful data reported, 4) other IL-1 $\beta$ polymorphisms than $-31 T / C$. Unpublished data were not considered. Disagreement was resolved by discussion before reaching a consensus. If more than one article was published by the same group using the same cases, the study with a higher sample size was selected.

\section{Statistical analysis}

Categorical variables are presented as odds ratio (OR) with $95 \%$ confidence interval $(\mathrm{Cl})$. CC, TC and TT are the genotypes of IL-1 $\beta-31 \mathrm{~T} / \mathrm{C}$ polymorphism. OR1, OR2 and OR3 were calculated as follows: OR1: CC vs. TT; OR2: TC vs. TT; OR3: CC vs. TC. These pairwise differences (OR1, OR2 and OR3) were used to indicate the most appropriate genetic model as follows: if OR $1=\mathrm{OR} 2 \neq 1$ and OR3 $=1$, then a dominant model was suggested; if OR1 =
$\mathrm{OR} 3 \neq 1$ and $\mathrm{OR} 2=1$, then a recessive model was suggested; if OR2 $=1 / \mathrm{OR} 3 \neq 1$ and $\mathrm{OR} 1=1$, then a complete overdominant model was suggested; if OR1 > OR2 > 1 and OR1 > OR3 > 1 (or OR1 < OR2 $<1$ and OR $1<$ OR3 < 1), then a codominant model was suggested. Once the best genetic model was identified, this model was used to collapse the three genotypes into two groups (except a codominant model) and to pool the results again. Pooled ORs with $95 \% \mathrm{Cl}$ were calculated and $p<0.05$ was accepted as statistical significance. Heterogeneity was checked by the $Q$ test. Meta-analysis was done with the fixed-effects model when there was no heterogeneity $(p \geq 0.1)$. Otherwise, the random-effects model was used. Subgroup analysis was performed by ethnicity to assess the effect of possible clinical heterogeneity on the summary ORs. Pearson's $\chi^{2}$ test was used to determine whether the observed frequencies of genotypes in controls conformed to the Hardy-Weinberg equilibrium (HWE). Studies with controls that depart from HWE $(p<0.05)$ were subjected to a sensitivity analysis in order to check the consistency of the overall effect size. Funnel plots, as well as Begg's rank correlation test and Egger's linear regression test, were used to assess the potential publication bias, and $p<0.05$ was considered significant publication bias. All analyses were conducted using Revman 5.0 (Oxford, UK, The Cochrane Collaboration) and Stata 11.0 (StataCorp LP, College Station, TX, USA) [12].

\section{Results}

\section{Studies included in the meta-analysis}

Sixteen studies were relevant to the search terms. After reviewing the titles, abstracts and articles, 11 studies were excluded; thus 5 articles with 6 case-control studies for $-31 \mathrm{~T} / \mathrm{C}$ matched the inclusion criteria (Figure 1). Of the 5 included

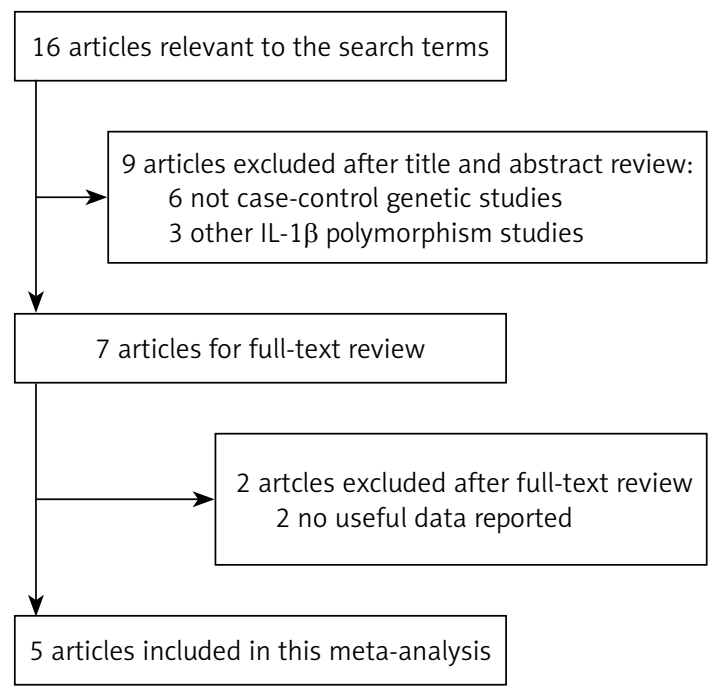

Figure 1. Flow diagram of search process 
Table I. Main characteristics of included studies

\begin{tabular}{|c|c|c|c|c|c|c|c|c|c|c|c|c|c|}
\hline \multirow[t]{2}{*}{ Ref. } & \multirow[t]{2}{*}{ Country } & \multirow[t]{2}{*}{ Race } & \multirow[t]{2}{*}{ Genotyping } & \multirow{2}{*}{$\begin{array}{c}\text { Source of } \\
\text { control }\end{array}$} & \multicolumn{4}{|c|}{ COPD } & \multicolumn{5}{|c|}{ Control } \\
\hline & & & & & Total & CC & TC & TT & Total & CC & TC & TT & HWE $(p)$ \\
\hline [4] & Japan & Asian & $\begin{array}{l}\text { PCR + } \\
\text { RFLP }\end{array}$ & $\begin{array}{l}\text { Healthy } \\
\text { population }\end{array}$ & 68 & 20 & 32 & 16 & 85 & 20 & 40 & 25 & 0.8771 \\
\hline [5] & Japan & Asian & $\begin{array}{l}\text { PCR + } \\
\text { RFLP }\end{array}$ & $\begin{array}{l}\text { Healthy } \\
\text { population }\end{array}$ & 88 & 16 & 52 & 20 & 60 & 8 & 31 & 21 & 0.8082 \\
\hline [5] & Egypt & Caucasian & $\begin{array}{l}\text { PCR + } \\
\text { RFLP }\end{array}$ & $\begin{array}{l}\text { Healthy } \\
\text { population }\end{array}$ & 105 & 11 & 45 & 49 & 71 & 16 & 29 & 26 & 0.3734 \\
\hline [6] & Korea & Asian & $\begin{array}{c}\mathrm{ABI} \\
\text { sequencer }\end{array}$ & $\begin{array}{l}\text { Healthy } \\
\text { men }\end{array}$ & 311 & 74 & 179 & 58 & 386 & 109 & 177 & 100 & 0.2696 \\
\hline [7] & China & Asian & $\begin{array}{l}\text { PCR + } \\
\text { RFLP }\end{array}$ & $\begin{array}{l}\text { Healthy } \\
\text { population }\end{array}$ & 162 & 29 & 101 & 32 & 162 & 27 & 99 & 36 & 0.0159 \\
\hline [8] & Taiwan & Asian & $\begin{array}{l}\text { PCR + } \\
\text { RFLP }\end{array}$ & $\begin{array}{l}\text { Healthy } \\
\text { population }\end{array}$ & 30 & 6 & 18 & 6 & 115 & 23 & 64 & 28 & 0.4665 \\
\hline
\end{tabular}

HWE - Hardy-Weinberg equilibrium, $P C R$ - polymerase chain reaction, Ref-reference, RFLP - restriction fragment length polymorphism

articles, 4 were published in English, and 1 was published in Chinese. These studies were carried out in China, Japan, Korea, Egypt, and Taiwan. Notably, the study by Hegab et al. [8] was performed in two ethnic populations (Japan and Egypt). The main features of the studies included in this meta-analysis are presented in Table I.

\section{Quantitative synthesis}

In order to indicate the most appropriate genetic model, OR1, OR2 and OR3 were calculated.
Results showed OR1 $=1.12$, OR2 $=1.38$ and OR3 $=0.80$ for $-31 \mathrm{~T} / \mathrm{C}$, suggesting an overdom inant genetic model (CC+TT vs. TC). The pooled effect size showed that there was a significant association of IL- $1 \beta-31 \mathrm{~T} / \mathrm{C}$ with the risk of COPD (OR: 0.77, 95\% Cl: 0.63-0.94, $p=0.009$, fixed model, Figure 2). In the subgroup analysis by ethnicity, the results indicated that IL-1 $\beta-31$ T/C was significantly correlated with COPD susceptibility in Asians (OR: $0.75,95 \% \mathrm{Cl}: 0.61-0.93, p=0.008$ fixed model, Figure 3).

\begin{tabular}{lcccccr} 
Studies & \multicolumn{1}{c}{ COPD $(n / N)$} & Control $(n / N)$ & Weight [\%] & OR $(95 \%$ Cl) \\
\hline Asada et al. 2005 & 36 & 68 & 45 & 85 & 8.6 & $1.00(0.53,1.89)$ \\
Hegab et al. 2005 & 36 & 88 & 29 & 60 & 9.3 & $0.74(0.38,1.43)$ \\
Hsieh et al. 2008 & 12 & 30 & 51 & 115 & 5.8 & $0.84(0.37,1.90)$ \\
Lee et al. 2008 & 132 & 311 & 209 & 386 & 48.8 & $0.62(0.46,0.84)$ \\
Liu et al. 2012 & 61 & 162 & 63 & 162 & 17.9 & $0.95(0.61,1.49)$ \\
Hegab et al. 2005 & 60 & 105 & 42 & 71 & 9.8 & $0.92(0.50,1.70)$ \\
Total (95\% Cl) & & 764 & & 879 & 100.0 & $0.77(0.63,0.94)$ \\
Total events & 337 & & 439 & & &
\end{tabular}

Heterogeneity: $\chi^{2}=3.72, \mathrm{~d} f=5(p=0.59), P^{2}=0 \%$

Test for overall effect: $Z=2.61(p=0.009)$

Test for subgroup differences: $\chi^{2}=0.39, \mathrm{~d} f=1(p=0.53), p^{2}=0 \%$

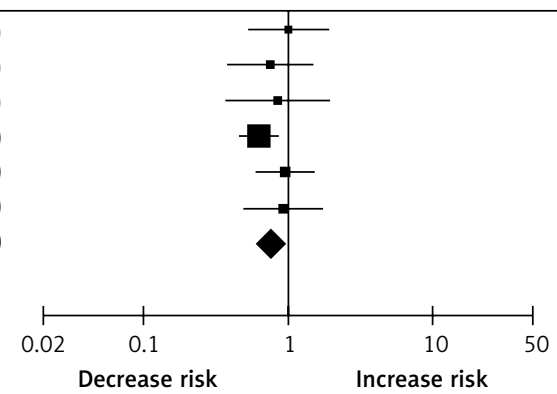

Figure 2. Forest plots of OR with $95 \% \mathrm{Cl}$ for the association of IL-1 $\beta-31 \mathrm{~T} / \mathrm{C}$ and COPD risk (CC+TT vs. TC)

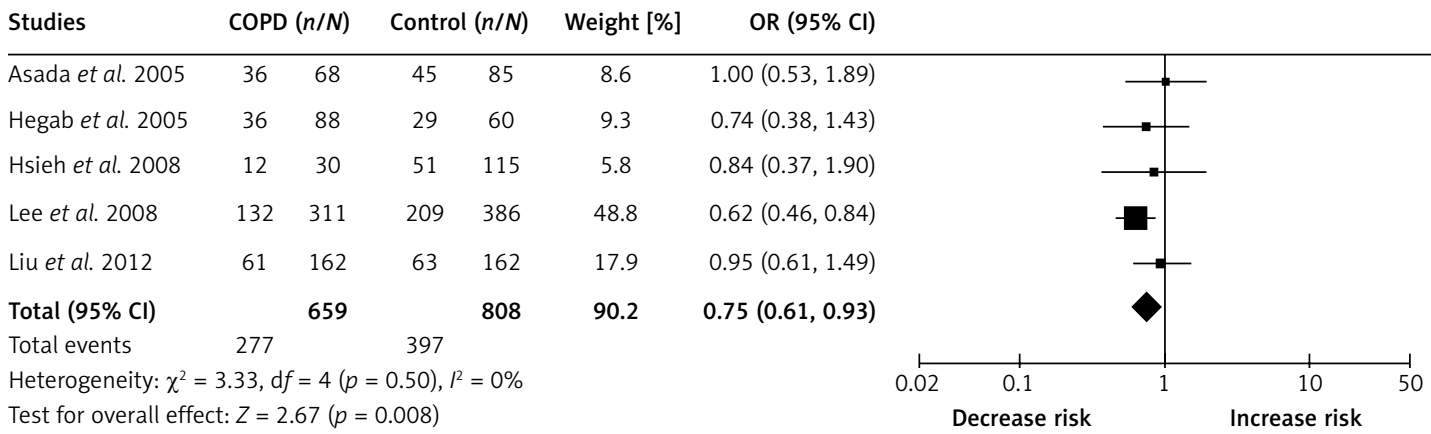

Figure 3. Forest plots of OR with $95 \% \mathrm{Cl}$ for the association of IL-1 $\beta-31 \mathrm{~T} / \mathrm{C}$ and COPD risk in Asians (CC+TT vs. TC) 


\section{Test of heterogeneity}

Significant heterogeneity was not revealed between all studies in CC+TT vs. TC comparison (overdominant model) for $-31 \mathrm{~T} / \mathrm{C}\left({ }^{2}=0 \%, p=0.59\right)$. When stratified by ethnicity, no heterogeneity was observed between the studies in Asians.

\section{Sensitivity analyses}

In the present meta-analysis, in only one study [10] was there lack of HWE, which had a potential to influence the robustness of the present meta-analysis. After exclusion of this study, the pattern of the pooled effect size persisted, while the overall heterogeneity was not significantly altered for $-31 \mathrm{~T} / \mathrm{C}\left(R^{2}=0 \%, p=0.62\right)$, indicating that this study might not contribute to the overall heterogeneity.

\section{Publication bias}

The funnel plots showed no significant asymmetry in this meta-analysis (Figure 4). Moreover, publication bias was not suggested by Begg's rank correlation test ( $p=1.000)$ or Egger's linear regression test $(p=0.138)$.

\section{Discussion}

IL-1 $\beta$, a proinflammatory cytokine, contributes to the pathogenesis of COPD. Recently, association of IL-1 $\beta-31 \mathrm{~T} / \mathrm{C}$ promoter polymorphism with COPD risk caught more attention, owing to its potential to alter the transcriptional activity.

The pooled effect size showed that IL-1 $\beta$ $-31 \mathrm{~T} / \mathrm{C}$ was significantly associated with COPD susceptibility in an overdominant genetic model, indicating that homozygotes (CC and TT) had a decreased risk for COPD compared with heterozygotes (TC). Significant heterogeneity was not revealed between all studies in CC+TT vs. TC comparison for $-31 \mathrm{~T} / \mathrm{C}$. In the subgroup analysis by ethnicity, the results indicated that IL-1 $\beta-31 \mathrm{~T} / \mathrm{C}$ was significantly correlated with COPD susceptibility in Asians, further suggesting a protective role of $\mathrm{IL}-1 \beta-31 \mathrm{~T} / \mathrm{C}$ in COPD pathogenesis in Asians. After exclusion of the study without HWE by Liu et al. [10], the pattern of the pooled effect size persisted, while the overall heterogeneity was not significantly altered for $-31 \mathrm{~T} / \mathrm{C}$, indicating that this study might not contribute to the overall heterogeneity. Publication bias was not suggested in the present study, possibly owing to the deliberate search strategy and data extraction.

However, some limitations should be considered in this meta-analysis. First, large sample size studies were lacking and the pooled statistical power might be insufficient. Second, the pooled estimates were not based on adjustment by con-

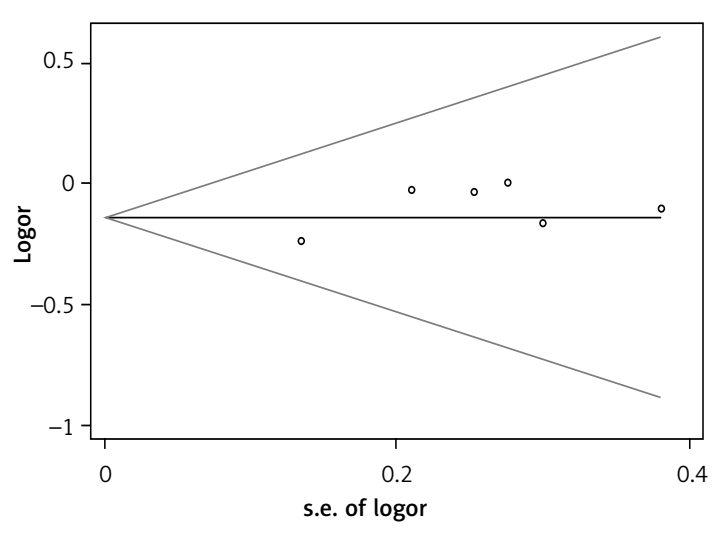

Figure 4. Begg's funnel plot for evaluation of publication bias in the included studies on the associations of IL-1 $\beta-31 \mathrm{~T} / \mathrm{C}$ with COPD risk

founding factors, such as sex, age, and smoking history. Third, the lack of original data in the studies limited our further analysis of the potential interactions between gene and gene, or gene and environment, which might modulate COPD risk.

In conclusion, although the pooled estimates should be interpreted with caution, our metaanalysis suggests that IL- $1 \beta-31 \mathrm{~T} / \mathrm{C}$ promoter polymorphism confers protection against COPD in Asians. However, large sample size studies with unbiased genotyping methods, standardized defined COPD cases and matched controls in different populations, as well as more detailed data about individual and environment, are warranted.

\section{Acknowledgments}

Min Xiao and Lingli Guo equally contributed.

This study was supported in part by an Application Infrastructure Project (2013JY0032) from the Science and Technology Department of Sichuan Province and grant 81230001 from the National Natural Science Foundation of China.

\section{References}

1. Global Strategy for Diagnosis, Management, and Prevention of COPD (Updated 2013).

2. Ezzeldin N, Shalaby A, Saad-Hussein A, et al. Association of TNF-alpha -308 G/A, SP-B 1580 C/T, IL-13 $-1055 \mathrm{C} / \mathrm{T}$ gene polymorphisms and latent adenoviral infection with chronic obstructive pulmonary disease in an Egyptian population. Arch Med Sci 2012; 8: 286-95.

3. Kurowski M, Majkowska-Wojciechowska B, Wardzyńska A, Kowalski ML. Associations of allergic sensitization and clinical phenotypes with innate immune response genes polymorphisms are modified by house dust mite allergen exposure. Arch Med Sci 2011; 7: 1029-36.

4. Antczak A, Ciebiada M, Pietras T, Piotrowski WJ, Kurmanowska Z, Górski P. Exhaled eicosanoids and biomarkers of oxidative stress in exacerbation of chronic obstructive pulmonary disease. Arch Med Sci 2012; 8: 277-85. 
5. Chung KF, Adcock IM. Multifaceted mechanisms in COPD: inflammation, immunity, and tissue repair and destruction. Eur Respir J 2008; 31: 1334-56.

6. Smolonska J, Wijmenga C, Postma DS, Boezen HM. Metaanalyses on suspected chronic obstructive pulmonary disease genes: a summary of 20 years' research. Am J Respir Crit Care Med 2009; 180: 618-31.

7. Asada M, Yamaya M, Ebihara S, et al. Interleukin-1beta gene polymorphisms associated with COPD. Chest 2005; 128: 1072-3.

8. Hegab AE, Sakamoto T, Saitoh W, et al. Polymorphisms of TNFalpha, IL1beta, and IL1RN genes in chronic obstructive pulmonary disease. Biochem Biophys Res Commun 2005; 329: 1246-52.

9. Lee JM, Kang YR, Park SH, et al. Polymorphisms in interleukin-1B and its receptor antagonist genes and the risk of chronic obstructive pulmonary disease in a Korean population: a case-control study. Respir Med 2008; 102: 1311-20.

10. Liu Y, Liu X, Li H, Wang L. Relationship between polymorphism of IL-1beta gene and chronic obstructive pulmonary disease in Han population. Zhong Guo Man Xing Bing Yu Fang Yu Kong Zhi 2012; 20: 128-31.

11. Hsieh MH, Chong IW, Hwang JJ, et al. Lack of associations between several polymorphisms in cytokine genes and the risk of chronic obstructivepulmonary diseases in Taiwan. Kaohsiung J Med Sci 2008; 24: 126-37.

12. Chen L, Shen Y, Liu L, Li X, Wang T, Wen F. Interleukin-13 $-1112 \mathrm{C} / \mathrm{T}$ promoter polymorphism confers risk for COPD: a meta-analysis. PloS One 2013; 8: e68222. 